\title{
Nonlinear seismic behaviour of experimentally identified stiffness and damping characteristics of cold formed steel infill frames
}

\author{
N. Bourahla ${ }^{1}$, B. El-Djouzi ${ }^{2} \&$ N. Allal $^{2}$ \\ ${ }^{I}$ Civil Engineering Department, University Saad Dahlab Blida, Algeria \\ ${ }^{2}$ R\&D Unit, ALRIM, Algiers, Algeria
}

\begin{abstract}
This paper evaluates the effect of wall panels, made of cold formed steel with sheathing on both sides used as infill, on the seismic behaviour of steel frames in terms of the overall additional stiffness and damping capacity. For this purpose, a series of ambient vibration testing was first carried out on a bare steel skeleton and then on a fully finished five-storey building. Based on the global characteristics of the panels, which were identified by experimental matching, a finite element modeling was made to reproduce the behaviour of the entire structure. The numerical model of the structure was subjected to a ground acceleration time histories recorded in the region during the Boumerdes 2003 earthquake. By using this procedure, inadequacies in the FE modeling are highlighted and suggestions are made for better modelling practice for similar structures. The results obtained elucidate some aspects of the stiffening and energy dissipating capacity role of the infill panels.
\end{abstract}

Keywords: cold formed steel, infill frame, earthquake response, ambient vibration, modeling technique, energy dissipation capacity.

\section{Introduction}

Cold-formed steel members and components have been produced and widely used as structural elements for building in many places around the world for at least three decades of the century. Modern design specifications have taken substantial steps in providing design analysis methodology, but these are 
becoming more complex, and can nowadays involve greater labour than rigorous analysis using numerical methods implemented in dedicated computer packages.

The design analysis of such structures is often complex, as their behaviour can be influenced by effects, which arise from the slenderness of members, walls and cross-sections. Prime among these effects are the various types of buckling which can occur, and which may interact with each other to promote failure at loads substantially less than those, which would be obtained in the absence of these effects. The complications induced by such effects occurred more often under severe earthquake loadings. Therefore, extensive experimental and analytical research work have been carried out to gain a better insight of the dynamic behaviour of shear walls and to establish design tables containing the ultimate capacities for static and seismic stress for different wall assemblies [1, 2]. Based on the results of large series of tests, design procedures and analytical methods were also developed to allow for the design of walls carrying horizontal and vertical loads $[3,4]$.

The overall seismic behaviour of cold formed structures has been also investigated in post-elastic domain. The performance of the building, as a whole, depends on the wall panels, which is governed by the performance of the connectors e.g.: sheeting-to-sheeting connectors, and sheeting-to-framing connectors. On the other hand the global behavior of the 3D structure of the building is significantly influenced by nonstructural elements, traditionally not considered explicitly in the design procedures (Dubina [5]). Finite element (FE) models were developed and proposed in recent years to predict the failure mechanisms and possibility of progressive collapse (Bae et al. [6]). Along with the lack of the implementation data of the guidelines, the FE models also needed to be investigated in terms of their accuracy and efficiency.

The intent of this paper is to evaluate the performance of a five storey hybrid building in terms of lateral displacement, energy dissipation capacity, and structural damage with a particular emphasis on the cold formed steel panels used as infill.

\section{Description of the structure}

A structure of a five-storey housing building was considered in this study. The layout of the ground floor is $30.0 \mathrm{~m}$ long and $23.0 \mathrm{~m}$ large. The skeleton of the building is made of hot rolled structural steel elements.

The frame infill is made of cold formed profiles with sections 400S200-43, 400S162-43 and 400S162-27, placed at $650 \mathrm{~mm}$ intervals. The studs and tracks are stiffened using $10 \mathrm{~mm}$ thick magnesium board (MagBoard) fixed to both sides (figs. 1 and 2). Material properties of the cold-formed steel used in this structure are for members of $1.14 \mathrm{~mm}$ thickness and lighter having minimum yield strength of 228MPa. All members $1.4 \mathrm{~mm}$ thickness and heavier were formed from steel with minimum yield strength of 345MPa.

This structure is designed to resist the dead load, live load, wind load and seismic load for Seismic Zone III (RPA99v2003, [7]). 


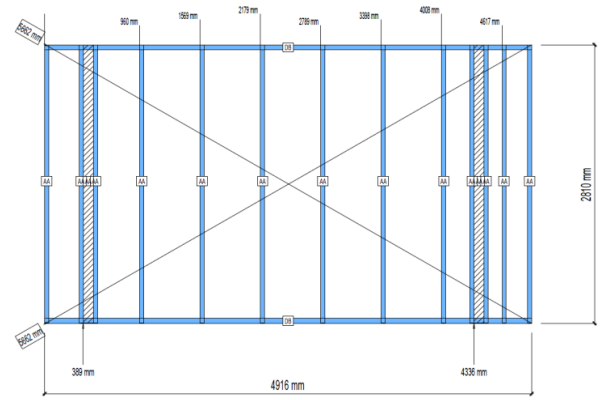

a- Panel frame w/o opening

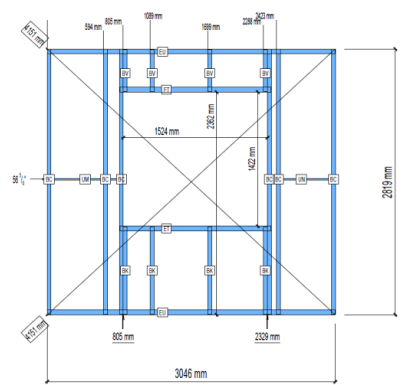

b- Panel frame with opening

Figure 1: $\quad$ Typical cold formed steel frame of wall panel.

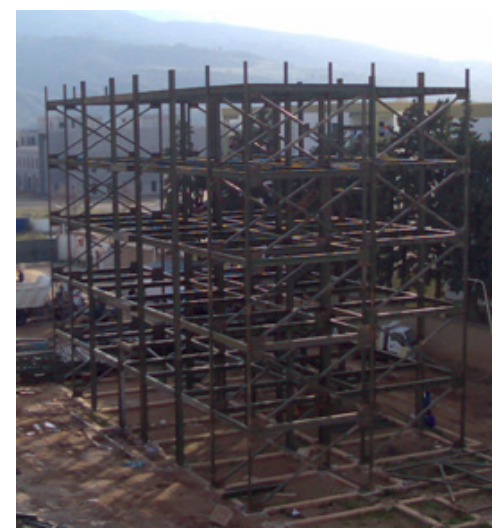

a- skeleton made of hot rolled steel

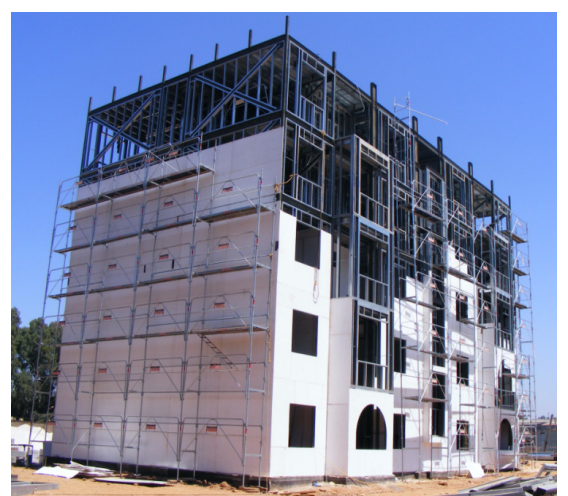

b- Infill panels made of cold formed steel

Figure 2: Global views of the building under construction.

\section{Numerical modelling}

The bare skeleton of the building is modelled using a 3-D finite element model. The beams and the columns are idealised as flexural elements and the diagonal as axial elements. The model was validated by an experimental modal analysis.

The floor decks and especially the non-bearing walls are modelled in order to evaluate the contribution of these elements in the overall nonlinear seismic behaviour of the building in terms of additional initial stiffness, modal damping and hysteresis energy dissipation capacity. Therefore, an equivalent simple nonlinear shear link connected to a rigid bracing system is introduced to account for the overall lateral stiffness and strength of a panel (fig. 3).

The multilinear plastic-pivot hysteresis model of the FEA software package, SAP2000 [8] was used to account for the nonlinear behavior of the cold formed steel panel. The hysteretic model incorporates stiffness degradation, strength deterioration and non-symmetric response (fig. 4). 


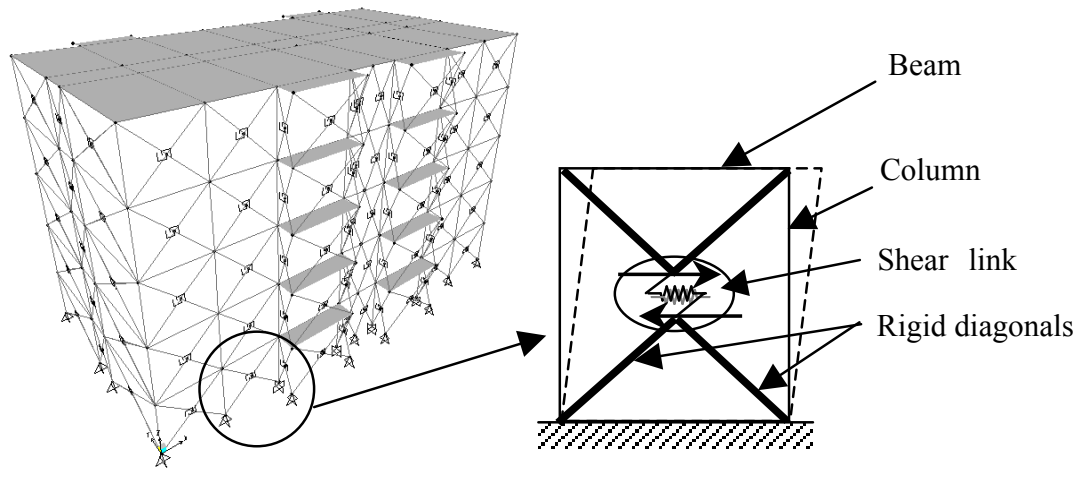

Figure 3: The 3-D model with an illustration of the shear link model of a panel.

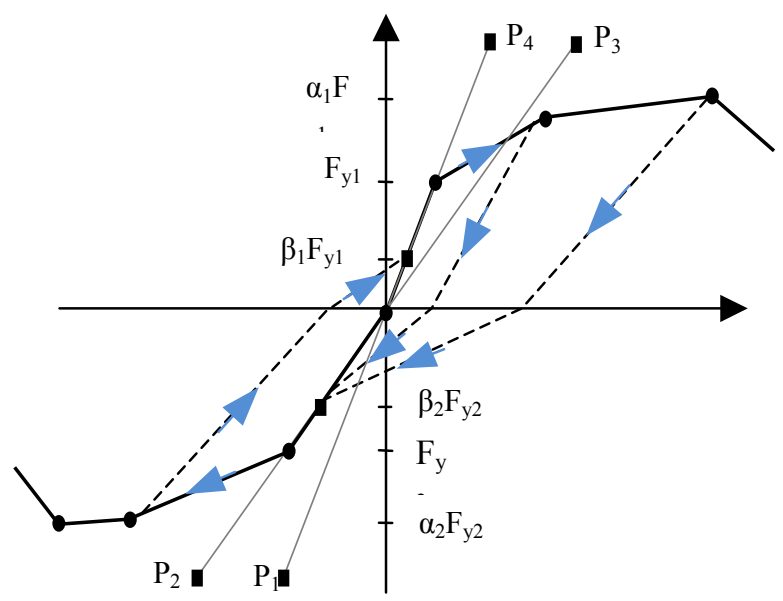

Figure 4: $\quad$ Multilinear plastic pivot hysteresis model [9].

The parameters of the hysteresis models are estimated through a number of load-deformation curves obtained experimentally under cyclic displacement histories, collected from a number of recent studies available in the literature [3, $9,10]$.

The structure has six different types of panels with different dimensions and openings. The relative elastic stiffness's were normalized using equivalent FE shell elements models, then the actual values of the initial stiffness was estimated by matching the building frequencies obtained experimentally using the ambient vibration testing. 


\section{Ambient vibration testing}

The elastic, mass and damping characteristics of the structure to be analysed must be known to a sufficient degree of accuracy in order to evaluate the actual structural capacity of the construction. The elastic dynamic properties, particularly the natural frequencies and the corresponding mode shapes are a combined measure of the structural characteristics of the construction. These model characteristics can be successfully estimated, especially in elastic range, using the well known ambient vibration testing. In this paper we present briefly the main issues pertaining to this particular modal testing; frequency response function (FRF) measurement techniques, testing procedure, and modal parameter estimation method.

For this particular case preliminary modal analyses were first carried out and the fundamental modes were predetermined. On the base of these results optimum sensor locations were chosen nevertheless additional measurement points were also included to take account of any other modes that were not predicted by the analytical model. Measurement near the nodal point of any of the modes will omit that particular mode and aliasing effect is to be prevented by avoiding intersection regions of the fundamental modes to be identified.

In total 4 measurement points were performed. Fig. 5 shows the locations and the orientations of the sensors on the $4^{\text {th }}$ floor.

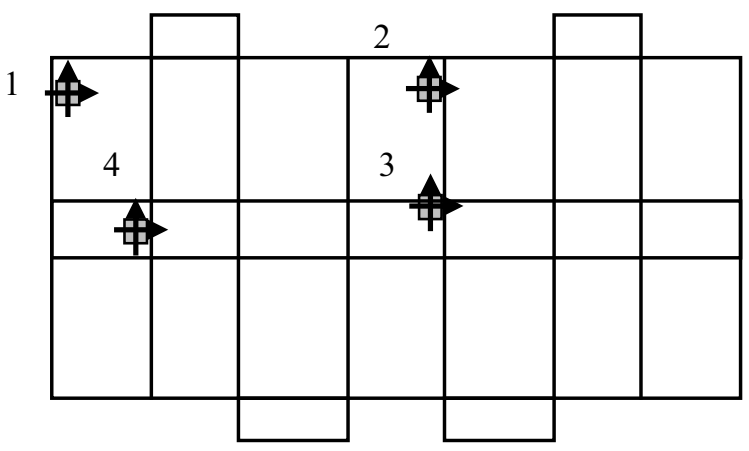

Figure 5: $\quad$ Sensor locations on the structure.

The tests were performed using three degrees of freedom seismometer type Lennartz electronic (Le3Dlite) and a data acquisition system type City Shark II. The measured signals were processed using the GEOPSY program (Wathelet [11]) capable to perform most of the signal processing operations for the analysis of ambient vibration data. The sensors were located and oriented according to the previously defined test programme. The recording time for each sequence was set to $5 \mathrm{mn}$ and found to be largely sufficient to obtain smooth FRF curves. 


\subsection{Ambient vibration measurement on the bare skeleton of the building}

The natural frequencies of the bare skeleton were first identified using a "peak cursor" on the frequency response functions. Due to the flexibility of the floors (without decks), the individual vibration modes do not exhibit translational motions of rigid diaphragms, but generally the mode shapes have deformed floors especially along the transversal direction.

The first curve in fig. 6 shows the FRF of the transverse vibrations measured on the centre of the top floor. The clearly distinct two first peaks at $1.56 \mathrm{~Hz}$ and $2.32 \mathrm{~Hz}$ correspond to the first and second translational mode determined by the model in the transverse direction. Because of the very stiff braced bays at the edges of the building, the flexible floor deformed excessively at the centre. The second FRF curve was measured by a sensor located at point 4 to detect the vibration modes of the braced bays. The latter shows a peak at a frequency equal to $10.25 \mathrm{~Hz}$ which corresponds to a higher vibration mode of the model as shown on the same figure. The dominant longitudinal vibration mode was successfully identified using the sensor located on point 4 at a frequency equal to $3.2 \mathrm{~Hz}$ together with a second peak at $4.51 \mathrm{~Hz}$ corresponding to a torsional mode.
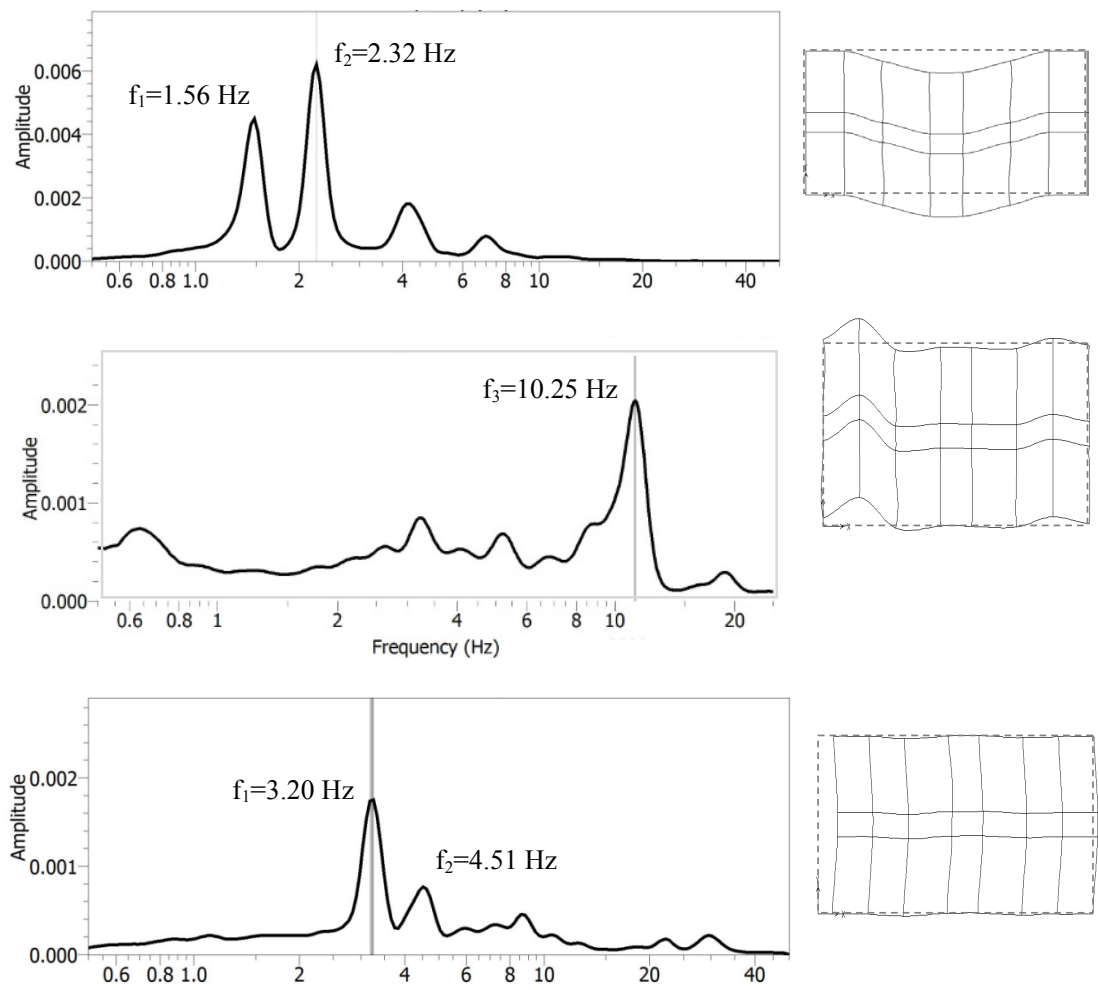

Figure 6: The FRF curves and the corresponding mode shapes (skeleton). 
In general, excellent correlation between experimental and analytical natural frequencies is achieved in most cases as can be seen from Table 1 .

Table 1: Natural frequencies and corresponding damping ratios of the bare skeleton.

\begin{tabular}{|c|c|c|c|c|}
\hline Mode & $\begin{array}{c}\text { Analytical } \\
\text { Frequency }(\mathrm{Hz})\end{array}$ & $\begin{array}{c}\text { Experimental } \\
\text { Frequency }(\mathrm{Hz})\end{array}$ & Direction & $\begin{array}{c}\text { Damping } \\
(\%)\end{array}$ \\
\hline 1 & 1.59 & 1.56 & Transversal & 0.5 \\
\hline 2 & 2.45 & 2.32 & Transversal & 0.4 \\
\hline 3 & 3.57 & 3.20 & Longitudinal & 0.4 \\
\hline 4 & 4.43 & 4.51 & Longitudinal & 0.3 \\
\hline 5 & 11.8 & 11.3 & Torsional & 0.3 \\
\hline
\end{tabular}

\subsection{Ambient vibration measurement on the completed building}

In order to account for the overall rigidity contribution of the cold formed decks (for floor) and the cladding, series of ambient vibration testing similar to the previous one have been carried out on a fully finished building.

We noticed that the first frequency equal to $3.48 \mathrm{~Hz}$ corresponds to a dominant longitudinal mode. The building becomes stiffer in the transverse direction with a frequency equal to $4.65 \mathrm{~Hz}$ and the mode shapes have nondeformable floors.
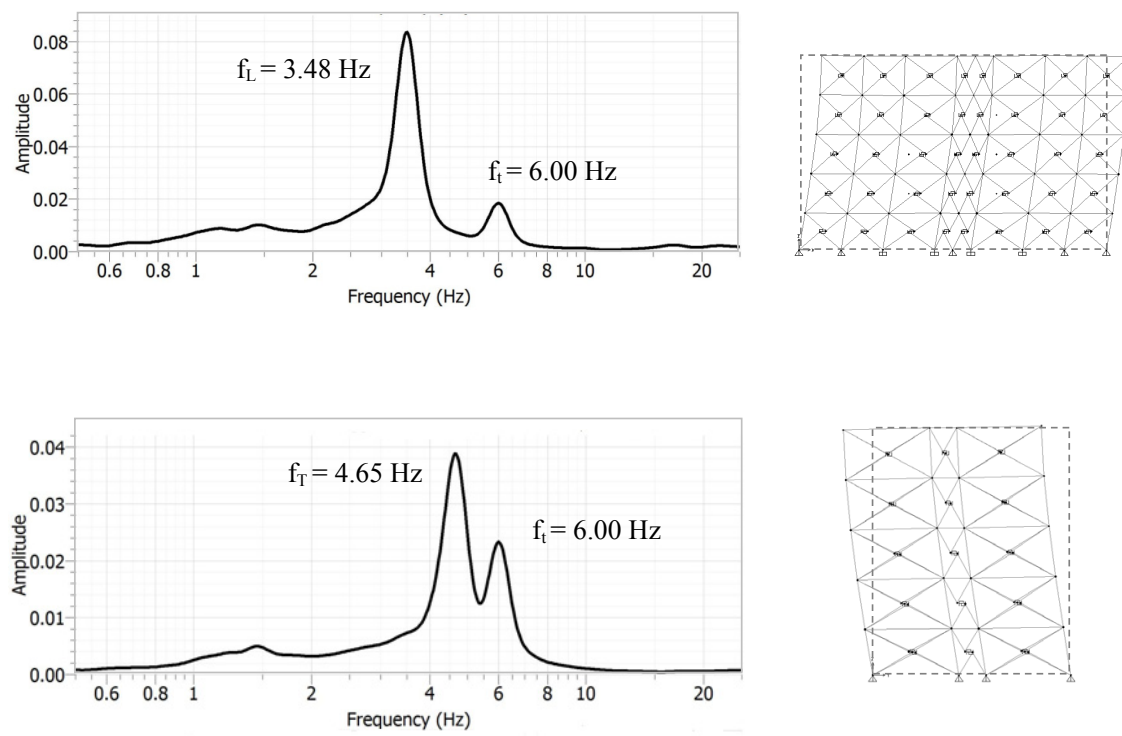

Figure 7: $\quad$ FRF curves and corresponding mode shapes (full building). 


\section{Evaluation of the stiffness and damping contribution of the cold formed steel infill}

In first instance, an evident increase of the overall rigidity is achieved by the non-bearing cold-formed steel panels in the horizontal directions. The substantial increase of the frequency along the transverse direction (more than 200\%) is attributed to the fact that the lateral panels have no openings beside that the decks stiffen the floors and eliminate the flexible modes of the floors which makes the skeleton bracing system more efficient. As can be seen in table 2 the modal damping has increased for all modes.

Table 2: Natural frequencies and corresponding damping ratios of the completed building.

\begin{tabular}{|c|c|c|c|c|}
\hline Mode & $\begin{array}{c}\text { Analytical } \\
\text { Frequency }(\mathrm{Hz})\end{array}$ & $\begin{array}{c}\text { Experimental } \\
\text { Frequency }(\mathrm{Hz})\end{array}$ & Direction & $\begin{array}{c}\text { Damping } \\
(\%)\end{array}$ \\
\hline 1 & 3.69 & 3.48 & Transversal & 0.6 \\
\hline 2 & 4.63 & 4.65 & Transversal & 1.4 \\
\hline 3 & 5.26 & 6.00 & Longitudinal & 1.0 \\
\hline
\end{tabular}

\section{Nonlinear dynamic analysis}

Nonlinear dynamic analyses are carried out to investigate the overall behavior of the building under earthquake ground motion. For the purpose of the present analysis the model described previously is subjected to a ground acceleration recorded during Boumerdes earthquake in 2003, at a station located in Dar-ElBeida (about $40 \mathrm{~km}$ from the building site). The duration of the strong motion used for the analysis is 20 seconds. The response analysis is carried out using the E-W component with a PGA equal to $0.52 \mathrm{~g}$. Modal damping has been included in the model and this was set at $5 \%$ for all modes as is usual practice for steel structures. The step-by-step numerical integration is carried out at time interval 1/1000 sec.

For a comparison reason, a linear dynamic analysis is performed assuming that all elements remain in the elastic range. The global response measured in terms of the top floor displacement indicates that the overall behaviour is dominated by the fundamental frequency (fig. 8).
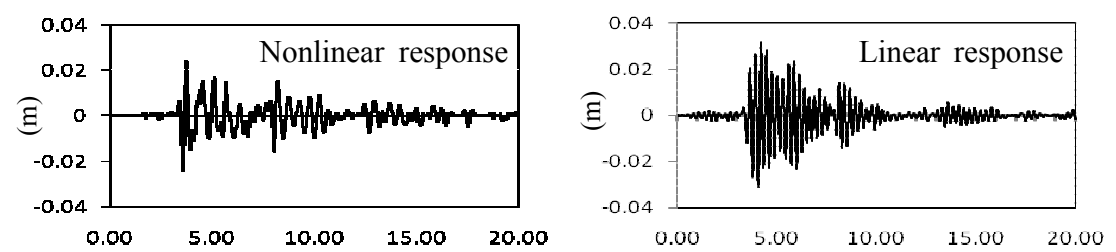

Figure 8: Time history of the top floor lateral displacement. 
Under the same earthquake ground motion conditions to which the linear model has been subjected, the structure with plastic pivot multi-linear characteristics exhibit different behaviour. At an early stage several panels undergo plastic deformations at the lower storey and propagate to the upper storeys during the severe phase of the ground acceleration. The building showed evidence of a considerable variation of the overall stiffness, which become visible on the response time history characterized by an elongated waveform (Fig. 9). The maximum displacement of the top floor is about $30 \%$ lower than the linear model and more importantly, the vibration are damped out after the main peak acceleration with almost no permanent deformation at the end of the response.

The low yield strength of the panels provide the building with an additional energy dissipation capacity at an early stage of the response which help damp out intense vibration and detune the structure from possible resonance. The energy dissipated by hysteresis effect of the infill panel is more than $30 \%$ of the modal damping energy of the structure. The curve of the input energy is characterized by small fluctuations, which reveal that the energy imparted by the ground motion to the structure is dissipated almost instantaneously which indicate an efficient damping capacity (Fig. 9). It should be noted also that the yielding is not concentrated only in the lower storey. The panel shear-deformation curves show significant hysteresis loops even on the panels of the upper storey.
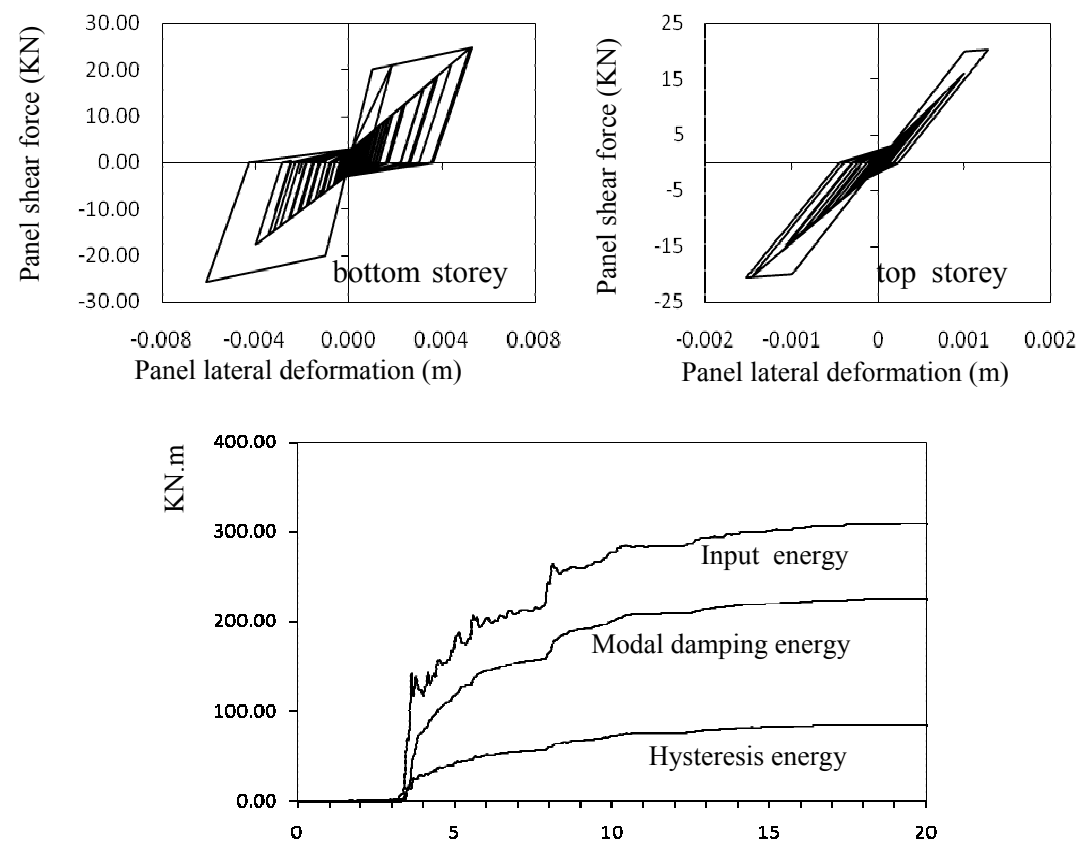

Figure 9: Energy time histories and shear-deformation curves of the panel walls. 


\section{Conclusion}

The non-bearing walls are commonly discarded in the design practice of buildings. This research showed that in the case of flexible steel frames with wall panels, made of cold-formed steel with sheathing on both sides used as infill, the latter can contribute significantly to the overall rigidity and energy dissipation capacity. The ambient vibration testing used at different construction stages is practical in evaluating the global characteristics of the wall panels.

An efficient simplified modeling technique for the analysis of structures incorporating wall panels is developed. The model presented is based on the multilinear plastic pivot hysteresis curve, but any suitable relationship could be used. This makes it particularly attractive for nonlinear response history analysis, but could be of great help for engineers to perform nonlinear static analysis (pushover) both in the design stage or the seismic evaluation of existing structures.

\section{References}

[1] Serrette R., Hall G. and Ngyen H., Shear wall values for light weight steel framing, final report, AISI, Washington, 1996.

[2] Serrette R., Hall G. and Encalada J., Additional shear wall values for light weight steel framing., Final report, AISI, Washington, 1997.

[3] Langea J. and Naujoksb B., Behaviour of cold-formed steel shear walls under horizontal and vertical loads, Thin-Walled Structures, 44 (2006), pp. 1214-1222, 2006.

[4] Al-Kharat M. and Rogers C. A., Inelastic performance of cold-formed steel strap braced walls, Journal of Constructional Steel Research, 63(4), pp. 460-474, 2007.

[5] Dubina D., Behavior and performance of cold-formed steel-framed houses under seismic action, Journal of Constructional Steel Research, 64 (2008), pp. 896-913, 2008.

[6] Bae S., LaBoube R. A., Belarbi A. and Ayoub A., Progressive collapse of cold-formed steel framed structures, Thin Wall Structures, 46 (2008), pp. 706-719, 2008.

[7] RPA99v2003, Regles parasismiques algeriennes, National Earthquake Engineering Centre CGS, Algiers, 2003.

[8] Computer and Structures, Inc. CSI analysis reference manual for Sap2000. Berkeley, 2004.

[9] Gad E.F., Duffield C.F., Hutchinson G.L., Mansella D.S. and Starkb G., Lateral performance of cold formed steel framed domestic structures, Engineering Structures, 21 (1999), pp. 83-95, 1999.

[10] Fulop L.A., and Dubina D., Performance of wall-stud cold-formed shear panels under monotonic and cyclic loading Part II: Numerical modelling and performance analysis, Thin-Walled Structures 42 (2004), pp. 339-349, 2004.

[11] Wathelet M., GEOPSY geophysical Signal Database for Noise Array Processing, Software, LGIT, Grenoble, France, 2005. 